\title{
Predicting functional disability in patients with spondyloarthritis using a CRP-based algorithm: A 3-year prospective study
}

\author{
LILIANA CATAN $^{1}$, MARIUS BOARIU ${ }^{2}$, ELENA AMARICAI $^{1}$, DANIEL POPA ${ }^{1,3}$, GEORGE PUENEA $^{1}$, \\ MIHAI DRĂGOI ${ }^{1,3}$, ȘTEFAN STRATUL $^{4}$ and RĂZVAN GABRIEL DRĂGOI ${ }^{1,3}$ \\ Departments of ${ }^{1}$ Balneology, Medical Rehabilitation and Rheumatology, and ${ }^{2}$ Endodontics, \\ 'Victor Babes' University of Medicine and Pharmacy, 300041 Timisoara; \\ ${ }^{3}$ Rehabilitation and Rheumatology Department, City University and Emergency Hospital, \\ 300020 Timisoara; ${ }^{4}$ Department of Periodontology, 'Victor Babes' University \\ of Medicine and Pharmacy, 300041 Timisoara, Romania
}

Received August 11, 2020; Accepted September 10, 2020

DOI: $10.3892 /$ etm.2020.9521

\begin{abstract}
This prospective study explored the link between values of C-reactive protein (CRP) in patients with SpA (ankylosing spondylitis, psoriatic arthritis, reactive arthritis, or arthritis-related inflammatory bowel disease) and functional disability in order to derive an algorithm that may predict functional disability based on disease activity. Patients diagnosed with Spa were classified into five groups based on the type of therapy and they were followed up for 3 years. Group 1: Symptomatic medication alone; Group 2: Disease-modifying antirheumatic drugs (DMARDs); Group 3: DMARDs and 30 rehabilitation sessions twice a year; Group 4: Group 3 therapy and biologic anti-tumor necrosis factor-alpha (anti-TNF- $\alpha$ ) drugs; and Group 5: Group 4 therapy and, in addition, a daily home-adapted kinesiotherapy program. CRP, modified Health Assessment Questionnaire (mHAQ-S), Bath Ankylosing Spondylitis Disease Activity Index (BASDAI), and T-score of the patients were recorded. Correlation and multivariate regression analyses were conducted using demographic data, CRP, and mHAQ-S scores to derive the CRP-mHAQ-S correlation algorithm. Statistical analysis included the chi-square, Mann-Whitney, and multiple regression tests and repeated measures analysis of variance. A total of 144 patients were enrolled, all of whom completed the study. The best predictive model $(\mathrm{P}<0.001)$ provided the algorithm mHAQ $_{36}=17.14+0.12 \mathrm{xCRP}_{0}-0.24 \mathrm{xCRP}_{12}-0.15 \mathrm{xCRP}_{36}\left(\mathrm{CRP}_{0}\right.$,
\end{abstract}

Correspondence to: Dr Marius Boariu, Department of Endodontics, 'Victor Babes' University of Medicine and Pharmacy, 9 Bulevardul Revolutiei din 1989, 300041 Timisoara, Romania E-mail: boarium@yahoo.com

Key words: C-reactive protein, disease activity, functional disability, HAQ-S, quality of life, spondyloarthritis
$\mathrm{CRP}_{12}$, and $\mathrm{CRP}_{36}$ correspond to $\mathrm{CRP}$ levels at baseline, 12 , and 36 months, respectively, and $\mathrm{mHAQ}-\mathrm{S}_{36}$ to $\mathrm{mHAQ}-\mathrm{S}$ score at 36 months). This derived algorithm based on objective CRP assessment may have implications in the prediction of functional disability evolution in patients with $\mathrm{SpA}$.

\section{Introduction}

Spondyloarthritis (SpA) is a group of chronic inflammatory rheumatic diseases comprising ankylosing spondylitis (AS), psoriatic arthritis (PsA), reactive arthritis (ReA), arthritis-related inflammatory bowel disease (IBD), and a subgroup of juvenile idiopathic arthritis $(1,2)$. In Europe, the incidence of SpA is variable, ranging from 1.5 to 10.6 for AS, 3.6 to 8 for PsA, and 9.3 to 28 for ReA per 100,000 population (3). Because delay in treatment could have important medical $(4,5)$ and socioeconomic implications (1) that could lead to severe disability, early diagnosis and treatment are essential. Recommendations of the European League Against Rheumatism (EULAR) advise that nonsteroidal anti-inflammatory drugs (NSAIDs) are the first-line treatment for patients with AS and PsA $(6,7)$. Anti-tumor necrosis factor-alpha (anti-TNF- $\alpha$ ) drugs are recommended directly after failure of conventional treatments in AS (6) but are third in line in PsA treatment after the failure of synthetic disease-modifying antirheumatic drugs (DMARDs) (7). Physiotherapy and kinesiotherapy are essential components of ReA treatment, with NSAIDs and steroids as first- and second-line therapies, respectively $(8,9)$. In contrast, NSAIDs are contraindicated in the treatment of the arthritis component of arthritis-related IBD, where, DMARDs and biologic anti-TNF- $\alpha$ drugs are effective therapeutics $(10,11)$.

Clinical management of SpA is based on assessment of disease activity (determined by clinical signs and symptoms and levels of acute phase reactants), structural changes, functional impairment, extra-articular manifestations, comorbidities, and treatment risks, with specific assessments that differ based on the type of SpA (12). Various objective, 
subjective, and composite indices are used to assess disease activity and functional disability of different types of SpA. The merits of some of these indices have been described previously $(9,11,13,14)$. The acute-phase reactant $\mathrm{C}$-reactive protein (CRP) is an established measure of disease activity in AS (13), PsA (14), and ReA (15) and is included in several composite indices to increase sensitivity $(16,17)$.

The Health Assessment Questionnaire Modified for Spondyloarthropathies (HAQ-S) can be used to assess functional disability in AS, PsA, ReA, as well as arthritis-related IBD (18-20). The HAQ-S, modified from the original HAQ instrument includes spinal mobility for SpA (21), being a patient-reported outcome (PRO) based on the assessment of disability, pain, medication effects, costs of care, and mortality (22). Such a multifaceted analysis of functional disability is part of the quality of life (QoL) assessment (23), which involves assessment of the overall perception of QoL (global measures) and specific physical, psychological, social, and functional issues that reflect or contribute to QoL (subscale item measures) (24).

The present study aimed to determine the association between the disease activity assessment tool (BASDAI), CRP and the functional disability assessment tool mHAQ-S (HAQ-S with a modified scoring system) in patients with SpA.

\section{Patients and methods}

Study design. This prospective study was conducted from January 2015 to May 2018 in the Department of Balneology, Rehabilitation, and Rheumatology of the City University and Emergency Hospital. The study was designed, implemented, and reported in accordance with the International Conference on Harmonisation (ICH) Harmonized Tripartite Guidelines for Good Clinical Practice and the ethical principles stated in the Declaration of Helsinki, as approved by the Ethics Committee of the 'Victor Babeș' University of Medicine and Pharmacy, Timisoara, Romania. Patients were invited to participate in the study at one of the routine visits in the outpatient/inpatient clinic. All patients provided written informed consent for participation and use of the data collected by the research team.

Participants. Patients aged $\geq 18$ years of both sexes and diagnosed with SpA, including AS, PsA, ReA, or arthritis-related IBD, were included in the study. Patients who had received prior therapy with immunomodulating agents, steroids, or NSAIDs, those who discontinued immunomodulator treatment due to side effects or absence of therapeutic response, and treatment-naïve patients were included in the study and randomized into study groups accordingly.

Patients were excluded if they had severe cardiac (heart failure, unstable angina, uncontrolled hypertension, heart attack, or coronary bypass 3 months prior to inclusion in the study), metabolic (uncontrolled diabetes mellitus, uncontrolled thyroid or suprarenal disorders, or cachexia), respiratory (uncontrolled asthma or chronic obstructive pulmonary disease), hematologic (leukemia or blood coagulation disorders), or psychiatric disorders, malignant tumors, infectious diseases (tuberculosis, hepatitis, or acquired immunodeficiency syndrome), febrile syndrome, acute thrombophlebitis, alcohol dependency, participated in other concomitant clinical trials, or required surgical procedures. Pregnant and lactating women were also excluded.

Patient classification and assessment. Eligible patients were provided standard-of-care treatment and were classified into 5 groups based on the type of therapy. Group 1 comprised patients receiving symptomatic treatment (e.g., oral NSAIDs with or without gastric protection) based on their clinical and functional status and associated pathology. Group 2 included patients receiving the same treatment as Group 1 and additional DMARDs. Group 3 comprised patients receiving the same treatment as Group 2 along with a rehabilitation program of 30 sessions twice a year, including physical therapy with manual massage, electrotherapy, phototherapy, thermotherapy, aquatic therapy, and kinesiotherapy based on the pathology and clinical stage of the disease (active or chronic) and disease activity. Group 4 comprised patients receiving the same treatment as Group 3 in addition to biologic therapy (anti-TNF- $\alpha$ drugs). Group 5 comprised patients receiving the same treatment as Group 4 along with a daily home-adapted kinesiotherapy program administered by a rehabilitation specialist.

Patients were evaluated at the beginning of the study (baseline), then monthly for the first 3 months, every 3 months thereafter until the end of the first year, and every 6 months thereafter until the end of the third year. Assessments included CRP, Bath Ankylosing Spondylitis Disease Activity Index (BASDAI), mHAQ-S, and T-score (measured by Dual Energy $\mathrm{X}$-ray Absorption [DEXA] to assess bone mineral density).CRP levels of $<5 \mathrm{mg} / \mathrm{l}$ were considered normal (25). The scores for BASDAI, a PRO for disease activity, ranged from 0 (no disease activity) to 10 (maximal disease activity). The mHAQ-S scale was modified from the original instrument (18) from $0-3$ to $0-30$, to increase the resolution and hence sensitivity, of the scoring system. In this system, higher scores indicated a better QoL to accommodate patients' mindset of giving higher scores to better conditions. T-scores $>-1$ were considered normal (26).

Statistical analysis. Correlation and multivariate regression analyses were used to determine the best predictive model that defined the relationship between CRP and mHAQ-S. The model included demographic variables, including age, sex, and residential area (urban or rural), as well as CRP and mHAQ-S assessments at baseline. Repeated measures analysis of variance (ANOVA) was used to determine treatment efficacy among the groups, in terms of change from baseline in the BASDAI, CRP and mHAQ-S scores. Other statistical tests included the chi-square, Mann-Whitney, and multiple regression analyses. All P-values were two-sided with a significant level of 0.05 . Demographic and baseline characteristics were summarized using descriptive statistics. Statistical analyses were conducted using the Statistics software program (IBM-SPSS, version 18, 2010).

\section{Results}

Patient characteristics. Of the 1,170 patients screened, 144 met the eligibility criteria [AS $(n=78), \operatorname{PsA}(n=44), \operatorname{ReA}(n=12)$, arthritis-related IBD $(\mathrm{n}=10)]$ and completed the study (Table I). Data collected was statistically analyzed and interpreted. The 
Table I. Demographics and baseline characteristics.

\begin{tabular}{|c|c|c|c|c|c|c|}
\hline Characteristics & $1(n=48)$ & $2(n=24)$ & $3(n=24)$ & $4(n=24)$ & $5(n=24)$ & Total $n=144$ \\
\hline Mean age, years (SD) & $46.27(13.27)$ & $47.21(14.23)$ & $49.25(14.62)$ & $46.96(15.39)$ & $49.08(10.49)$ & $47.51(13.50)$ \\
\hline \multicolumn{7}{|l|}{$\operatorname{Sex}, n(\%)$} \\
\hline Men & $27(56.25)$ & $12(50.00)$ & $11(45.83)$ & $14(58.33)$ & $13(54.16)$ & $77(53.5)$ \\
\hline Women & $21(43.75)$ & $12(50.00)$ & $13(54.17)$ & $10(41.67)$ & $11(45.83)$ & $67(46.5)$ \\
\hline \multicolumn{7}{|l|}{ Disease, $n(\%)$} \\
\hline AS & $26(18.1)$ & $13(9.0)$ & $13(9.0)$ & $13(9.0)$ & $13(9.0)$ & $78(54.2)$ \\
\hline PsA & $16(11.1)$ & $8(5.6)$ & $8(5.6)$ & $6(4.2)$ & $6(4.2)$ & $44(30.6)$ \\
\hline $\operatorname{ReA}$ & $4(2.8)$ & $2(1.4)$ & $2(1.4)$ & $2(1.4)$ & $2(1.4)$ & $12(8.3)$ \\
\hline IBD & $2(1.4)$ & $1(0.7)$ & $1(0.7)$ & $3(2.1)$ & $3(2.1)$ & $10(6.9)$ \\
\hline $\mathrm{CRP}, \mathrm{mg} / \mathrm{l}$, mean $(\mathrm{SD})$ & $33.51(8.69)$ & $36.55(12.74)$ & $28.23(7.76)$ & $35.94(12.24)$ & $34.80(10.97)$ & $33.73(10.50)$ \\
\hline BASDAI, mean (SD) & $6.72(0.90)$ & $6.75(0.85)$ & $5.91(1.06)$ & $7.09(0.98)$ & $6.70(1.08)$ & $6.65(1.02)$ \\
\hline mHAQ-S, mean (SD) & $7.15(1.60)$ & $6.75(1.03)$ & $8.38(2.18)$ & $6.83(1.52)$ & $7.46(1.67)$ & $7.28(1.70)$ \\
\hline T-Score, mean (SD) & $-2.68(0.59)$ & $-2.77(0.54)$ & $-1.90(0.95)$ & $-2.24(0.73)$ & $-2.41(0.73)$ & $-2.42(0.73)$ \\
\hline
\end{tabular}

AS, ankylosing spondylitis; BASDAI ${ }_{0}$, Bath Ankylosing Spondylitis Disease Activity Index at baseline; IBD, arthritis-related IBD; CRP, C-reactive protein; mHAQ-S: modified Health Assessment Questionnaire Modified for Spondyloarthropathies; PsA: psoriatic arthritis; $\mathrm{n}$, number of patients; ReA, reactive arthritis; and SD, standard deviation.

average age $[ \pm$ standard deviation $(\mathrm{SD})]$ was $47.5( \pm 13.5)$ years and $53.3 \%$ were men, of whom $68.1 \%$ living in urban areas. Group 1 comprised 48 patients, while the rest of the groups (2, 3, 4 and 5) comprised 24 patients each.

Physical disability as a function of disease activity. A mathematic model was developed using correlation and regression analyses to objectively determine the functional disability in patients with SpA during a 3-year treatment period as follows:

$$
m H A Q-S_{36}=17.14+0.12 x C R P_{0}-0.24 x C R P_{12}-0.15 x C R P_{36}
$$

where $\mathrm{CRP}_{0}, \mathrm{CRP}_{12}$, and $\mathrm{CRP}_{36}$ correspond to $\mathrm{CRP}$ levels at baseline, 12, and 36 months, respectively, and mHAQ-S ${ }_{36}$ to mHAQ-S score at 36 months $[\mathrm{F}(7,136)=36.25 ; \mathrm{P}<0.001]$.

mHAQ-S scores at baseline did not significantly influence the model. CRP at baseline and 12 and 36 months showed $\beta$ equivalent to $0.12,-0.24$, and -0.15 , respectively, and the standardized $\beta$ equivalent to $0.14,-0.43$, and -0.38 , respectively, which significantly influenced the model (Table II). When $\beta$ increased by 1 unit, the mHAQ-S score increased by 0.043 units at baseline and decreased by 0.24 and 0.15 units at 12 and 36 months, respectively. Preliminary analyses were conducted to test the hypotheses of normality, linearity, and multicollinearity. The CRP levels at 24 months and BASDAI scores were excluded because they were collinear.

Efficacy analysis. Analysis of BASDAI, CRP, and mHAQ-S scores revealed significant between-treatment differences in efficacy. The scores were higher in Group 2 and 3 than in Group 1, whereas the scores in Group 4 and 5 were higher than in both Groups 1, 2 and 3; CRP: F [2,141]=171.54, P<0.001; BASDAI: F $[2,141]=178.16, \mathrm{P}<0.001$; mHAQ-S: $\mathrm{F}[2,141]=745.50, \mathrm{P}<0.001$; total T-score: $\mathrm{F}[2,141]=8.69, \mathrm{P}<0.001)$. Table III depicts a
Table II. Correlation and regression analysis of $\mathrm{HAQ}-\mathrm{S}_{36}$ values.

\begin{tabular}{|c|c|c|c|c|c|}
\hline \multirow[b]{2}{*}{ Model } & \multicolumn{2}{|c|}{$\begin{array}{l}\text { Unstandardized } \\
\text { coefficients }\end{array}$} & \multicolumn{2}{|c|}{$\begin{array}{l}\text { Standardized } \\
\text { coefficients }\end{array}$} & \multirow[b]{2}{*}{ Sig. } \\
\hline & $\mathrm{B}$ & SE & Beta & $T$ & \\
\hline \multicolumn{6}{|l|}{1} \\
\hline Age & 0.002 & 0.056 & 0.003 & 0.038 & 0.969 \\
\hline Sex & -0.281 & 1.474 & -0.016 & -0.191 & 0.849 \\
\hline Environment $^{\mathrm{a}}$ & 1.487 & 1.629 & 0.080 & 0.913 & 0.363 \\
\hline \multicolumn{6}{|l|}{2} \\
\hline Age & 0.011 & 0.034 & 0.018 & 0.340 & 0.734 \\
\hline Sex & -0.353 & 0.896 & -0.020 & -0.394 & 0.694 \\
\hline Environment $^{\mathrm{a}}$ & 0.813 & 0.978 & 0.044 & 0.831 & 0.408 \\
\hline $\mathrm{CRP}_{0}$ & 0.107 & 0.043 & 0.130 & 2.484 & 0.014 \\
\hline $\mathrm{CRP}_{12}$ & -0.245 & 0.067 & -0.440 & 3.639 & 0.000 \\
\hline $\mathrm{CRP}_{36}$ & -0.151 & 0.047 & -0.388 & -3.232 & 0.002 \\
\hline \multicolumn{6}{|l|}{3} \\
\hline Age & 0.013 & 0.034 & 0.021 & 0.387 & 0.699 \\
\hline Sex & -0.342 & 0.900 & -0.020 & -0.380 & 0.704 \\
\hline Environment $^{\mathrm{a}}$ & 0.804 & 0.982 & 0.043 & 0.819 & 0.414 \\
\hline $\mathrm{CRP}_{0}$ & 0.123 & 0.059 & 0.149 & 2.065 & 0.041 \\
\hline $\mathrm{CRP}_{12}$ & -0.243 & 0.068 & -0.437 & -3.588 & 0.000 \\
\hline $\mathrm{CRP}_{36}$ & -0.152 & 0.047 & -0.389 & -3.232 & 0.002 \\
\hline mHAQ-S $_{0}$ & 0.139 & 0.368 & 0.027 & 0.377 & 0.707 \\
\hline
\end{tabular}

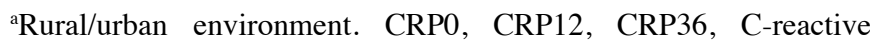
protein values at baseline, 12 months, and 36 months, respectively; mHAQ-S0, modified Health Assessment Questionnaire Modified for Spondyloarthropathy values at baseline; and SE, standard error. 
Table III. Disease activity and functional disability outcomes at 3-year follow-up.

\begin{tabular}{lccc}
\hline Items & Group & $\mathrm{n}$ & Mean (SD) \\
\hline CRP, mg/l & 1 & 48 & $51.91(16.72)$ \\
& 2 & 24 & $23.14(7.54)$ \\
& 3 & 24 & $20.90(5.61)$ \\
BASDAI & 4 & 24 & $6.31(2.10)$ \\
& 5 & 24 & $2.83(1.19)$ \\
& 1 & 48 & $7.43(0.68)$ \\
& 2 & 24 & $5.40(0.82)$ \\
mHAQ-S & 3 & 24 & $4.97(0.88)$ \\
& 4 & 24 & $2.03(0.52)$ \\
& 5 & 24 & $1.25(0.50)$ \\
T-score & 1 & 48 & $6.54(1.03)$ \\
& 2 & 24 & $8.67(1.01)$ \\
& 3 & 24 & $10.75(1.92)$ \\
& 4 & 24 & $23.38(1.66)$ \\
& 5 & 24 & $28.13(1.39)$ \\
& 2 & 48 & $-2.46(0.59)$ \\
& 3 & 24 & $-2.64(0.62)$ \\
& 4 & 24 & $-1.48(1.05)$ \\
& 5 & 24 & $-1.72(0.74)$ \\
& 5 & $-1.65(0.61)$ \\
\hline
\end{tabular}

CRP, C-reactive protein levels; BASDAI, Bath Ankylosing Spondylitis Disease Activity Index; mHAQ-S, modified Health Assessment Questionnaire Modified for Spondyloarthropathy values; $\mathrm{n}$, number of patients; and SD, standard deviation.

comparison of the average values of the parameters at the end of the study. No significant difference was observed in the average CRP and BASDAI values at 36 months between Groups 2 and 3 . However, the average CRP and BASDAI values in Group 5 were significantly lower than in Group 4 (Mann-Whitney values: $U=17, z=-5.59, \mathrm{P}<0.001$ and $U=71, z=-4.49, \mathrm{P}<0.001$, respectively). The average mHAQ-S score at the final assessment was significantly higher in Group 3 compared with Group 2 ( $U=74.5$, $z=-4.52, \mathrm{P}<0.001)$ and in Group 5 compared with Group 4 $(U=5.5, z=-5.89, \mathrm{P}<0.001$; Table III). The total T-score at the end of the study was significantly higher in Group 3 compared with Group $2(U=94.5, z=-3.99, \mathrm{P}<0.001)$ and in Group 5 compared with Group 4.

A mixed ANOVA was performed between the groups and their serial determinations to determine the impact of specific therapeutic approaches (differentiated group therapies) on the average values of CRP, BASDAI, mHAQ-S, and total T-score (at baseline and at 12,24, and 36 months). A statistically significant association was observed between the type of therapy and assessments at different evaluation time points (CRP, BASDAI, mHAQ-S, and total T-score; all P-values $<0.001$ ).

\section{Discussion}

Our study shows that CRP, an objective measure of disease activity, can be used as a surrogate PRO of functional disability, the HAQ-S instrument, if a history of CRP values is available. We propose an algorithm to measure the functional disability associated QoL at 36 months using CRP levels at baseline, 12, and 36 months. We believe that this algorithm may have implications in the clinical management of SpA as it would enable assessment of therapeutic efficacy and facilitate longitudinal follow-up, thereby promoting consistent treatment decisions. Even though updated information regarding biomarkers/immune markers that sustain the heterogeneity and complexity of psoriatic arthritis pathogenesis are studied, and new immune proteomic or genomic biomarkers can enlarge and identify new therapeutic targets (27), management of clinical implications of the disease remain the main concern of a clinician. Therefore, developing predictive models that serve as a surrogate measure for PRO would be particularly helpful in reducing the nonspecific effects observed in clinical trials, which result from inherent bias in PROs. PROs may introduce bias via the Hawthorne effect, wherein participants change their behavior because they are being observed, or via the Pygmalion effect, wherein participants augment their existing impairment at study inclusion and minimize it at follow-up to meet the expectations of the clinician or the sponsor (28).

Several studies have associated higher disease activity with higher functional disability. Disease activity was identified as one of the 2 independent determinants of physical function impairment in AS in the study variables (29) and was associated with reduced work efficiency in PsA (30), as some pathogenic mechanism involved in the development of psoriasis seems to produce disorders of the endogenous antioxidative systems (31). In addition, disease activity measured by CRP correlated with functional disability measured by the PRO Bath Ankylosing Spondylitis Functional Index (BASFI) in patients with short-term axial SpA treated with etanercept or adalimumab (32). The present study found a similar correlation between CRP and mHAQ-S. HAQ-S as a part of QoL assessment is one of the indicators of disease remission along with laboratory biomarkers, radiologic findings, disease activity, and functional markers. As such, HAQ-S assessment can potentially reduce costs associated with expensive investigations. A prospective study reported that remission in patients with PsA receiving biologic therapy was strongly associated with HAQ-S rather than other parameters such as global visual analog scores and early-morning stiffness (33).

The combination of medical treatment with rehabilitation and individualized daily home-adapted kinesiotherapy programs improved the disease activity as well as physical function, as determined by BASDAI and mHAQ-S scores, respectively. Our results are consistent with those of previous studies reporting improved QoL in patients with SpA who participated in physical exercise programs (34-36). In fact, physical exercise is an integral part of non-pharmacological AS treatment per 2010 EULAR recommendations (6). The sustained, long-term kinesiotherapy programs in patients with SpA may play a role in immunomodulation by activating anti-inflammatory and disease-modifying factors. If biomarkers that sustain the pathogenesis of SpA (24) are available, new immune proteomic or genomic biomarkers should be identified in order to evaluate the role of physical exercise on the human body.

This study has some limitations, such as the relatively small number of patients in each group and a 3-year 
follow-up period, which is considered short for a lifelong chronic disease. In addition, our study did not characterize disease duration. However, in PsA, increase in disease duration reduces the influence of disease activity on HAQ scores (37). Thus, in our study, differences in disease duration among the patients may have influenced the strength of the CRP-mHAQ-S association. The CRP-mHAQ-S algorithm was partly based on patients with arthritis-related IBD; in this condition, CRP is not considered an adequate measure of disease activity since it is also elevated in IBD unrelated to arthritis (11). Nevertheless, the proportion of patients with arthritis-related IBD was low in the overall patient population $(6.9 \%)$, potentially mitigating the effect to some extent.

Another limitation would be that a patient needs a history of CRP values over time in order to apply the algorithm. However, the algorithm can possibly be validated in an independent population, which may be undertaken in a future study, so it could pave the way for a more comprehensive understanding and use of it.

\section{Acknowledgements}

We thank Dr Costela Serban for her help in the statistical analysis of the study results. The authors retained full control of the manuscript content. All named authors meet the ICMJE criteria for authorship for this manuscript, take responsibility for the integrity of the work, and have given final approval for the version to be published.

\section{Funding}

No funding was received.

\section{Availability of data and materials}

The datasets used/analyzed in the present study are available from the corresponding author on reasonable request.

\section{Authors' contributions}

LC, EA, DP and GP participated in data acquisitions. MD, MB and RGD participated in the study design. All authors drafted the manuscript. SS and RGD critically revised the intellectual content of the manuscript. All authors read and approved the final version of the manuscript.

\section{Ethics approval and consent to participate}

The study was approved by the Ethics Committee of Timisoara University of Medicine and Pharmacy, Romania. All procedures were followed in accordance with the ethical standards of the responsible committee on human experimentation (institutional and national) and with the Helsinki Declaration of 1975, as revised in 2000 and 2008. All patients gave informed consent for participation.

\section{Patient consent for publication}

Not applicable.

\section{Competing interests}

The authors declare that they have no competing interests.

\section{References}

1. Bevan S: Spondyloarthropathy and Work. A Review of UK Evidence. The Work Foundation, London, 2010.

2. Dougados M and Baeten D: Spondyloarthritis. Lancet 377: 2127-2137, 2011.

3. Bakland G and Nossent HC: Epidemiology of spondyloarthritis: A review. Curr Rheumatol Rep 15: 351, 2013.

4. Arumugam R and McHugh NJ: Mortality and causes of death in psoriatic arthritis. J Rheumatol Suppl 89: 32-35, 2012.

5. Bakland G, Gran JT and Nossent JC: Increased mortality in ankylosing spondylitis is related to disease activity. Ann Rheum Dis 70: 1921-1925, 2011.

6. Braun J,van den Berg R,Baraliakos X, BoehmH,Burgos-Vargas R, Collantes-Estevez E, Dagfinrud H, Dijkmans B, Dougados M, Emery P, et al: 2010 update of the ASAS/EULAR recommendations for the management of ankylosing spondylitis. Ann Rheum Dis 70: 896-904, 2011

7. Gossec L, Smolen JS, Gaujoux-Viala C, Ash Z, Marzo-Ortega H, van der Heijde D, FitzGerald O, Aletaha D, Balint P, Boumpas D, et al: European league against rheumatism recommendations for the management of psoriatic arthritis with pharmacological therapies. Ann Rheum Dis 71: 4-12, 2012.

8. Palazzi C, Olivieri I, D'Amico E, Pennese E and Petricca A: Management of reactive arthritis. Expert Opin Pharmacother 5: 61-70, 2004.

9. Kwiatkowska B and Filipowicz-Sosnowska A: Reactive arthritis. Pol Arch Med Wewn 119: 60-65, 2009.

10. Orchard TR: Management of arthritis in patients with inflammatory bowel disease. Gastroenterol Hepatol (NY) 8: 327-329, 2012.

11. Arvikar SL and Fisher MC: Inflammatory bowel disease associated arthropathy. Curr Rev Musculoskelet Med 4: 123-131, 2011.

12. Smolen JS, Braun J, Dougados M, Emery P, Fitzgerald O, Helliwell P, Kavanaugh A, Kvien TK, Landewé R, Luger T, et al: Treating spondyloarthritis, including ankylosing spondylitis and psoriatic arthritis, to target: Recommendations of an international task force. Ann Rheum Dis 73: 6-16, 2014.

13. Braun J, Kiltz U, Baraliakos X and van der Heijde D: Optimisation of rheumatology assessments - the actual situation in axial spondyloarthritis including ankylosing spondylitis. Clin Exp Rheumatol 32 (Suppl 85): S96-S104, 2014.

14. Salaffi F, Ciapetti A, Carotti M, Gasparini S and Gutierrez M: Disease activity in psoriatic arthritis: Comparison of the discriminative capacity and construct validity of six composite indices in a real world. BioMed Res Int 2014: 528105, 2014.

15. Eberl G, Studnicka-Benke A, Hitzelhammer H, Gschnait F and Smolen JS: Development of a disease activity index for the assessment of reactive arthritis (DAREA). Rheumatology (Oxford) 39: $148-155,2000$.

16. van der Heijde D, Lie E, Kvien TK, Sieper J, Van den Bosch F, Listing J, Braun J and Landewé R; Assessment of SpondyloArthritis international Society (ASAS): ASDAS, a highly discriminatory ASAS-endorsed disease activity score in patients with ankylosing spondylitis. Ann Rheum Dis 68: 1811-1818, 2009.

17. Helliwell PS, FitzGerald O, Fransen J, Gladman DD, Kreuger GG, Callis-Duffin K, McHugh N, Mease PJ, Strand V, Waxman R, et al: The development of candidate composite disease activity and responder indices for psoriatic arthritis (GRACE project). Ann Rheum Dis 72: 986-991, 2013.

18. Zochling J: Measures of symptoms and disease status in ankylosing spondylitis: Ankylosing Spondylitis Disease Activity Score (ASDAS), Ankylosing Spondylitis Quality of Life Scale (ASQoL), Bath Ankylosing Spondylitis Disease Activity Index (BASDAI), Bath Ankylosing Spondylitis Functional Index (BASFI), Bath Ankylosing Spondylitis Global Score (BAS-G), Bath Ankylosing Spondylitis Metrology Index (BASMI), Dougados Functional Index (DFI), and Health Assessment Questionnaire for the Spondylarthropathies (HAQ-S). Arthritis Care Res (Hoboken) 63 (Suppl 11): S47-S58, 2011.

19. Gladman DD, Mease PJ, Healy P, Helliwell PS, Fitzgerald O, Cauli A, Lubrano E, Krueger GG, van der Heijde D, Veale DJ, et al: Outcome measures in psoriatic arthritis. J Rheumatol 34: 1159-1166, 2007. 
20. Rohekar S and Pope J: Assessment of work disability in seronegative spondyloarthritis. Clin Exp Rheumatol 28: 35-40, 2010.

21. Daltroy LH, Larson MG, Roberts NW and Liang MH: A modification of the Health Assessment Questionnaire for the spondyloarthropathies. J Rheumatol 17: 946-950, 1990.

22. Bruce B and Fries JF: The Health Assessment Questionnaire (HAQ). Clin Exp Rheumatol 23 (Suppl 39): S14-S18, 2005.

23. Kotsis K, Voulgari PV, Drosos AA, Carvalho AF and Hyphantis T: Health-related quality of life in patients with ankylosing spondylitis: A comprehensive review. Expert Rev Pharmacoecon Outcomes Res 14: 857-872, 2014.

24. Kifley A, Heller GZ, Beath KJ, Bulger D, Ma J and Gebski V: Multilevel latent variable models for global health-related quality of life assessment. Stat Med 31: 1249-1264, 2012.

25. Machado P and van der Heijde D: How to measure disease activity in axial spondyloarthritis? Curr Opin Rheumatol 23: 339-345, 2011.

26. Singh HJ, Nimarpreet K, Ashima, Das S, Kumar A and Prakash S: Study of bone mineral density in patients with ankylosing spondylitis. J Clin Diagn Res 7: 2832-2835, 2013.

27. Caruntu C, Boda D, Dumitrascu G, Constantin C and Neagu M: Proteomics focusing on immune markers in psoriatic arthritis. Biomarkers Med 9: 513-528, 2015.

28. Berthelot JM, Le Goff B and Maugars Y: The Hawthorne effect: Stronger than the placebo effect? Joint Bone Spine 78: 335-336, 2011.

29. Landewé R, Dougados M, Mielants $H$, van der Tempel $H$ and van der Heijde D: Physical function in ankylosing spondylitis is independently determined by both disease activity and radiographic damage of the spine. Ann Rheum Dis 68: 863-867, 2009.

30. Tillett W, Shaddick G, Askari A, Cooper A, Creamer P, Clunie G, Helliwell PS, Kay L, Korendowych E, Lane S, et al: Factors influencing work disability in psoriatic arthritis: First results from a large UK multicentre study. Rheumatology (Oxford) 54: 157-162, 2015.
31. Boda D, Negrei C, Nicolescu F and Badalau C: Assessment of some oxidative stress parameters in methotrexate treated psoriasis patients. Farmacia 62: 704-710, 2014.

32. Weiss A, Song IH, Haibel H, Listing J and Sieper J: Good correlation between changes in objective and subjective signs of inflammation in short- but not long-diseased patients with axial spondyloarthritis treated with tumor necrosis factor-blockers. Arthritis Res Ther 16: R35, 2014.

33. Saber TP, Ng CT, Renard G, Lynch BM, Pontifex E, Walsh CA, Grier A, Molloy M, Bresnihan B, Fitzgerald O, et al: Remission in psoriatic arthritis: Is it possible and how can it be predicted? Arthritis Res Ther 12: R94, 2010.

34. O'Dwyer T, O'Shea F and Wilson F: Exercise therapy for spondyloarthritis: A systematic review. Rheumatol Int 34: 887-902, 2014.

35. Mesquita C, Lopes S, Excelsa Moreira M, Lopes P, Carneiro A, Silva D, Neves I, Araújo F and Vitorino A: A2.8 Effect of home exercise program in quality of life in patients with ankylosing spondylitis. Ann Rheum Dis 73 (Suppl 1): A41, 2014.

36. van den Berg R, Baraliakos X, Braun J and van der Heijde D: First update of the current evidence for the management of ankylosing spondylitis with non-pharmacological treatment and non-biologic drugs: A systematic literature review for the ASAS/EULAR management recommendations in ankylosing spondylitis. Rheumatology (Oxford) 51: 1388-1396, 2012.

37. Husted JA, Tom BD, Farewell VT, Schentag CT and Gladman DD: A longitudinal study of the effect of disease activity and clinical damage on physical function over the course of psoriatic arthritis: Does the effect change over time? Arthritis Rheum 56: 840-849, 2007. 